\title{
Antinociceptive effect of Salvia Sharifii Rech. F. \& Esfand seed's oil in formalin test in mice
}

Zahra Mousavi ${ }^{1}$, Jinous Asgarpanah ${ }^{2}$, Farzaneh Heydarzadeh ${ }^{3}$, Ava Zenderood ${ }^{3}$, Yas Arbabi ${ }^{3}$, Rana Kharazchi ${ }^{3}$ ${ }^{1}$ Department of Pharmacology and Toxicology, Faculty of Pharmacy and Pharmaceutical Sciences, Tehran Medical Sciences, Islamic Azad University, Tehran- Iran

${ }^{2}$ Department of Pharmacognosy, Faculty of Pharmacy and Pharmaceutical Sciences, Tehran Medical Sciences, Islamic Azad University, Tehran- Iran

${ }^{3}$ Roshangaran Girls' High School in Tehran, Iran

\begin{abstract}
Background: Salvia sharifii Rech. F. \& Esfand (Lamiaceae) is an Iranian endemic plant that widely used as a medicinal plant. Due to the antinociceptive and anti-inflammatory effects of other Salvia species, the present study was conducted to investigate the antinociceptive effect of $S$. sharifii seed's oil (SSSO) in experimental animals.

Materials and methods: Seed's oil of $S$. sharifii was extracted by Soxhlet method. In order to assess the antinociceptive activity, the animals were classified to five groups: control (vehicle), S. sharifii seed's oil (20 and $100 \mathrm{mg} / \mathrm{kg}$ ) and standard groups (morphine $5 \mathrm{mg} / \mathrm{kg}$ and mefenamic acid $30 \mathrm{mg} / \mathrm{kg}$ ). The analgesic activities were studied by formalin test in mice. The nociceptive responses were divided to two phases; phase I (0-15minutes) and phase II (15-60 minutes). Comparisons between the groups were carried out using the analysis of variance (one way ANOVA) and post hoc Tukey's test. $\mathrm{P}<0.05$ was considered as significant difference.

Results: S. sharifii seed's oil showed significant antinociceptive effects in first phase (dose $20 \mathrm{mg} / \mathrm{kg}$ ) and second phase (dose 20 and $100 \mathrm{mg} / \mathrm{kg}$ ) of formalin test compared to control group. These effects were comparable to morphine and mefenamic acid in chronic phase of formalin test.

Conclusion: The results indicated that $S$. sharifii seed's oil induced a significant antinociceptive in mice that is likely related to active constituents of this seed's oil.

Keywords: Antinociceptive, Salvia Sharifii Rech.f. \& Esfand, Seed's Oil, Mice.

Cited as: Mousavi Z, Asgarpanah J, Heydarzadeh F, Zenderood A, Arbabi Y, Kharazchi R. Antinociceptive Effect of Salvia Sharifii Rech. f. \& Esfand Seed's Oil in formalin test in mice. Medical Science Journal of Islamic Azad University, Tehran Medical Branch 2019; 29(1): 18-26.
\end{abstract}

Correspondence to: Zahra Mousavi

Tel: +989125081304

E-mail: mosavi50@yahoo.com

ORCID ID: 0000-0001-6524-491X

Received: 25 Aug 2018; Accepted: 17 Oct 2018 
مجله علوم يزشكى دانشگًاه آزاد اسلامى

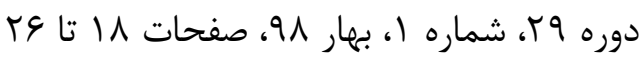

\section{اثر ضد درد روغن دانههاى مريم كلى جنوبى (Salvia sharifii Rech. F. \& Esfand) در آزمون فرمالين در موش سورى نر}

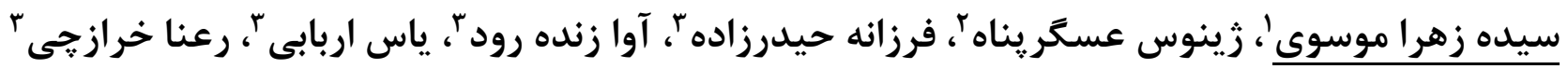

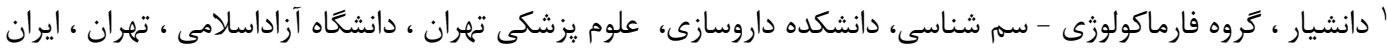

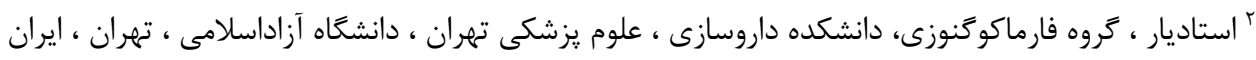

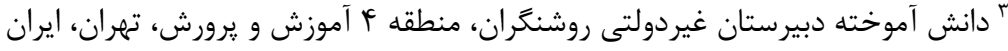

سابقه و هدف: مريم كلى جنوبى (Salvia sharifii Rech. F. \& Esfand) /ز خانواده Lamiaceae به عنوان يك كياه دارويى،

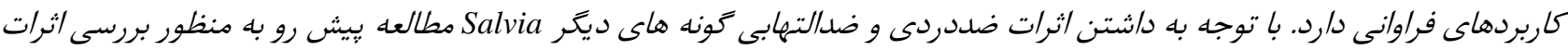

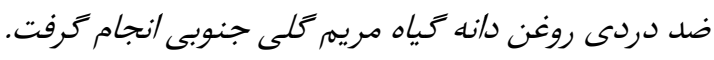

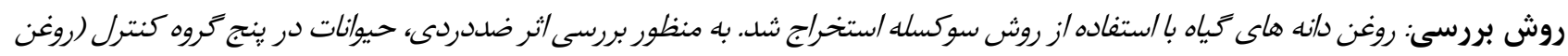

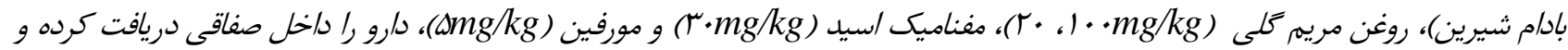

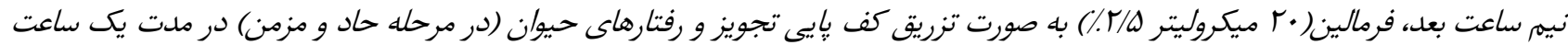

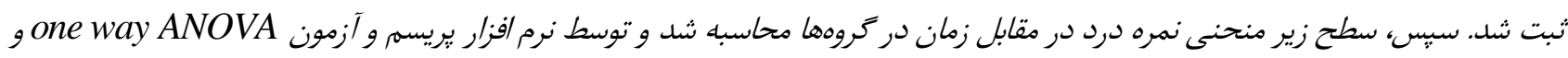

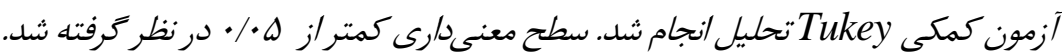

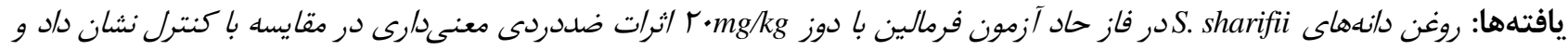

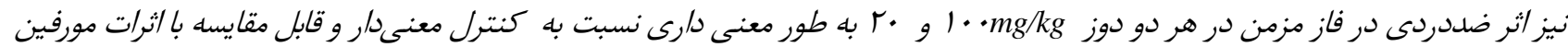
و مفناميك /سيد بود.

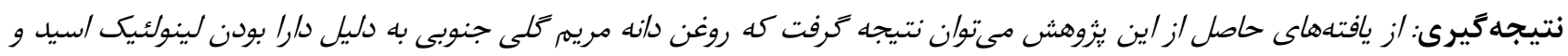

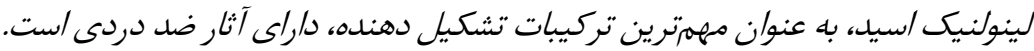
وازّكان كليدى: ضد درد، مريم كلى جنوبى، روغن دانهانى كياه، موش كوجك.

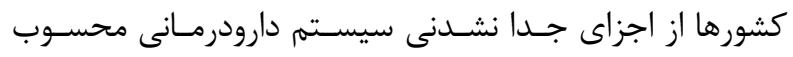
مقدمه

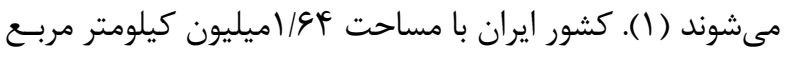

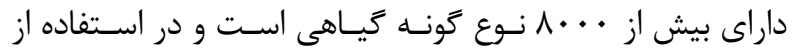

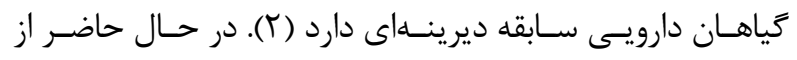

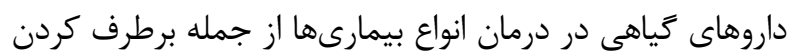
درد و التهاب استفاده مىشود و تحقيقات وسيعى در اين زمينــهـ

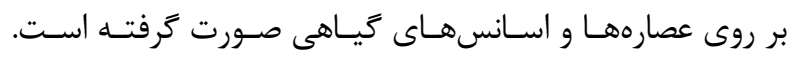

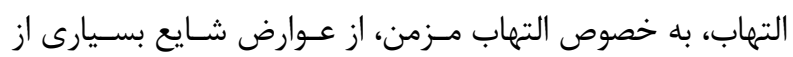
با وجود يیشرفت و توسعه جشمخير در كاربرد داروهاى ســنتزى،

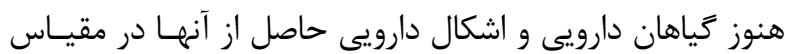

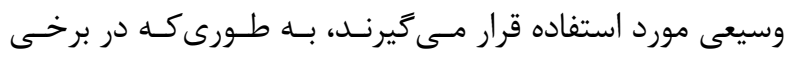

آدرس نويسنده مسئول: تهران، دانشخاه علوم بزشكى آزاد اسـلامى تهـران، دانشـكده داروسـازى و علـوم : دارم

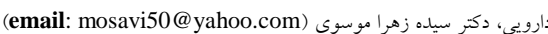
ORCID ID: 0000-0001-6524-491X

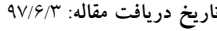
تاريخ هذيرش مقاله: QV/V/IV 


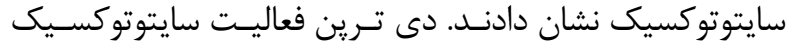

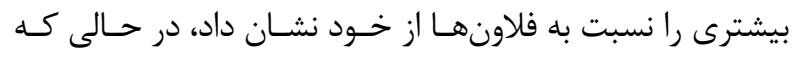

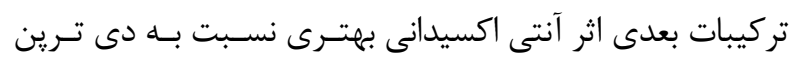

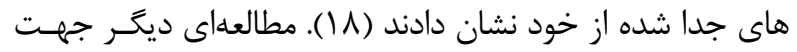

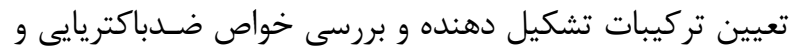

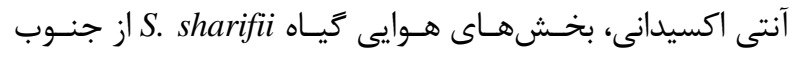

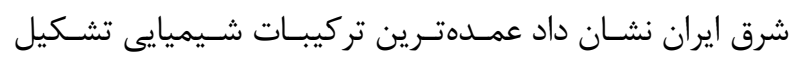

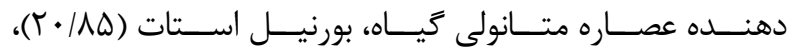

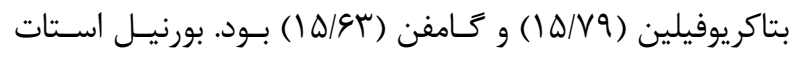

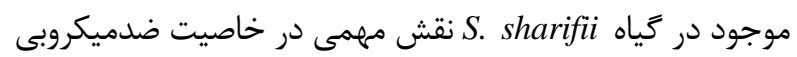

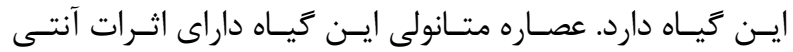
اكسيدانى قابل توجهى است (19).

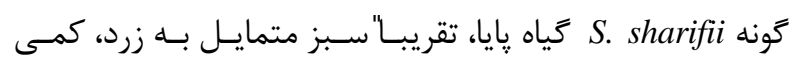
يوشيده از كرك هاى متراكم غير غده اى با غده يوش و يوشـيده

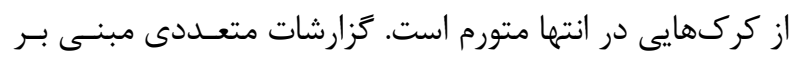

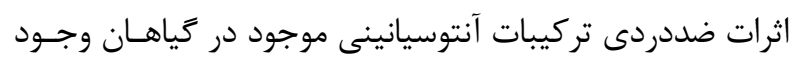
دارد. تجويز عصارههاى كياهى سرشار از اين مواد در كاهش دردي درد

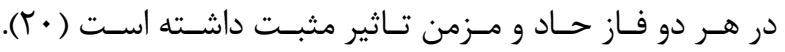

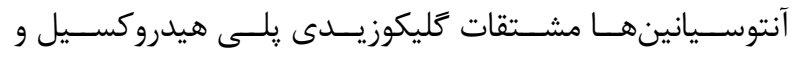

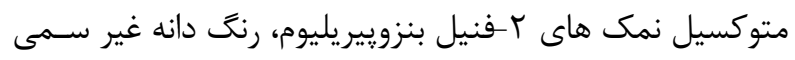
و محلول در آب هستند كه به طور گستردهاى در طبيعت يافت آنس

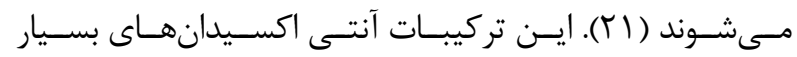

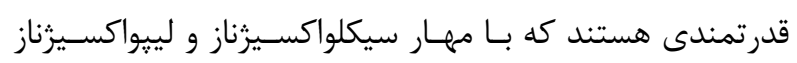

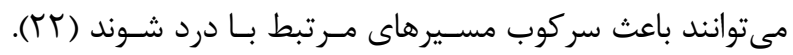

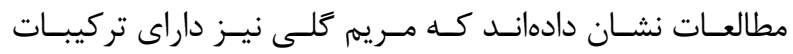

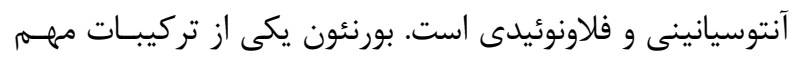

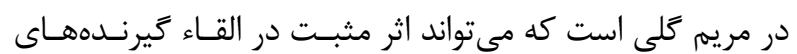

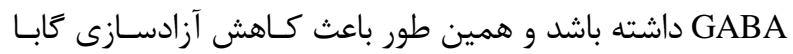

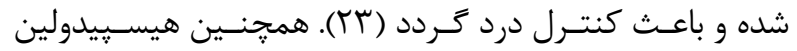

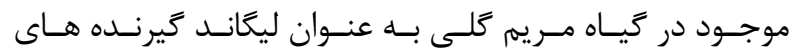

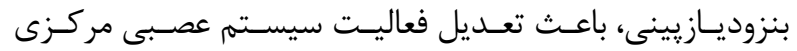

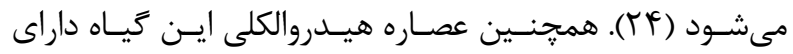

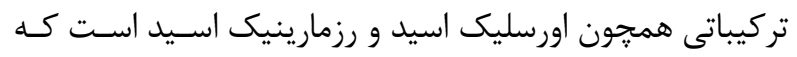

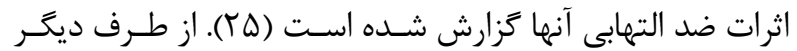

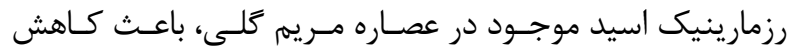

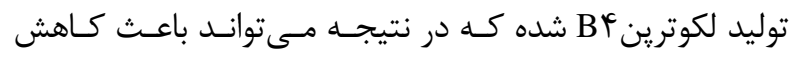

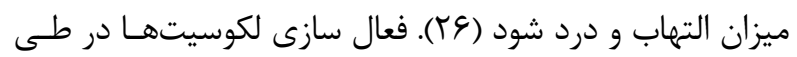

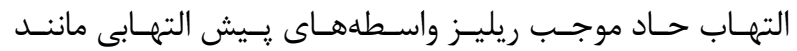

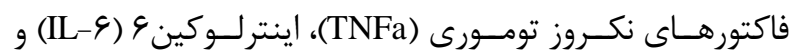

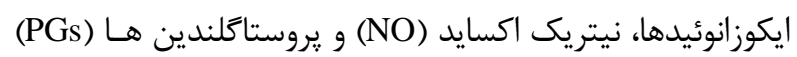

بيمارىهاست كه باعث تضعيف سيستم ايمنى مىشود. اسـتفاده

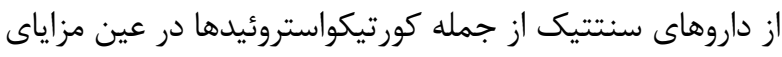

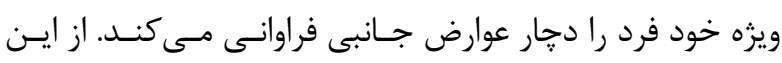

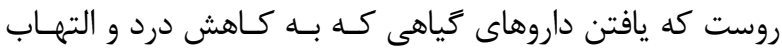
كمك مى كنند حائز اهميت است.

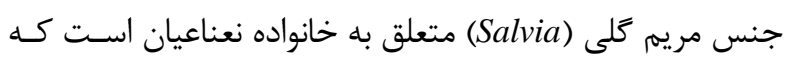

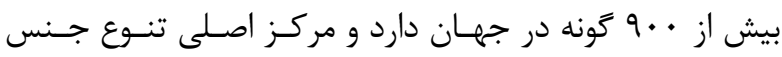

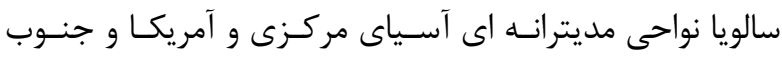

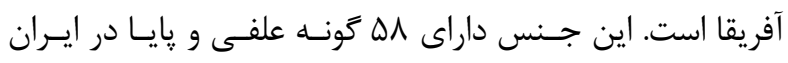

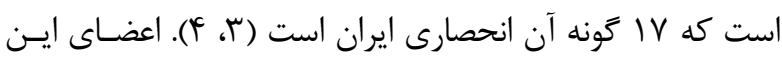

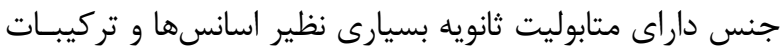
فنولى است كه داراى خواص دارويى است و در مقابل پـاتوزنهـا

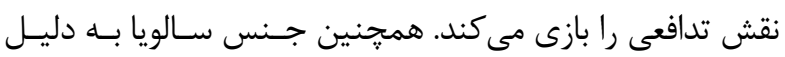

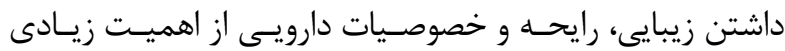

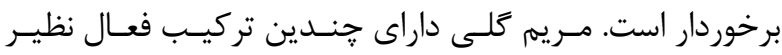

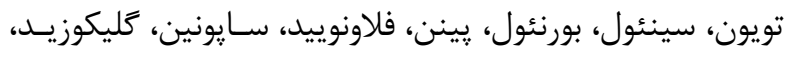

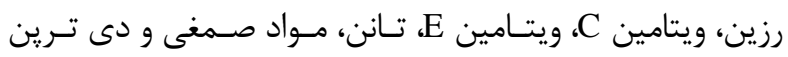
است (ه). از دير باز بشر به اين نكته بيى برده است كه كَونههـاى دئين

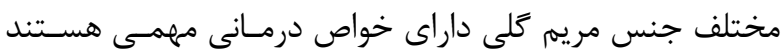

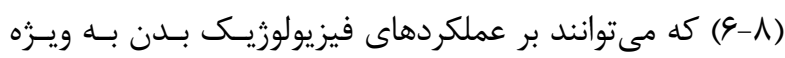

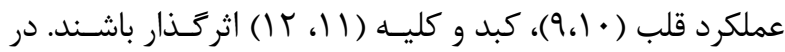
طب سنتى مريم كلى به عنوان داروى موثر براى معالجه عوارض

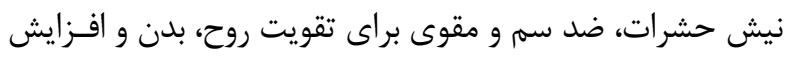

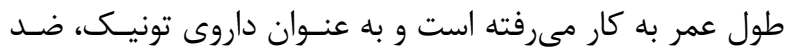

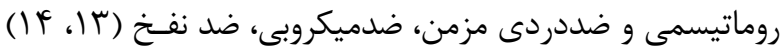

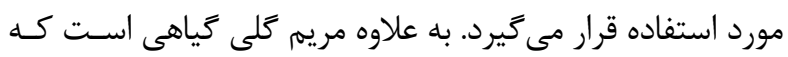

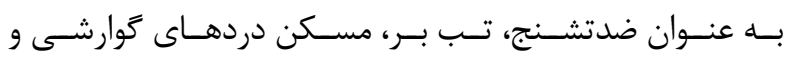

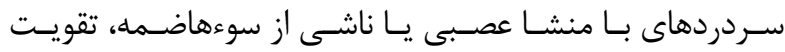

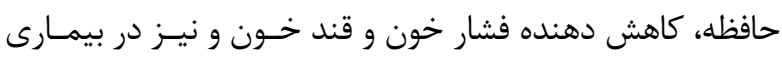
ميكرن مورد استفاده قرار مى كيرد (ه) (ل).

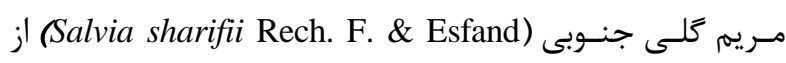

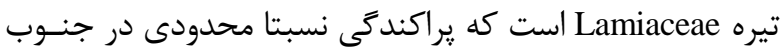
ايران، به خصوص استان هرمز كان، دارد و كَونه انحصـارى ايـران

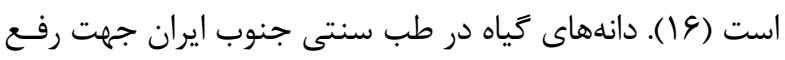
دل درد، سردرد، زخمه، اسهال، سينه درد، سرماخوردگى استفادئ

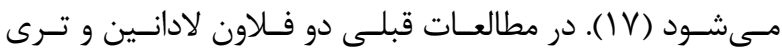

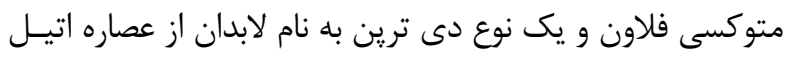

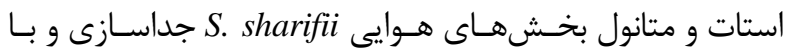
استفاده از روشهاى مختلف كروماتوكرافى خالص سازى شـدندات

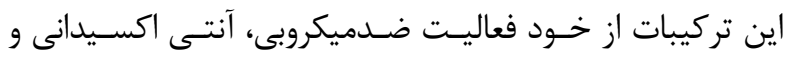


گروه Y: دريافت كننده مفناميـك اسـيد mg/kg · بــهـ صـورت داخل صفاقى

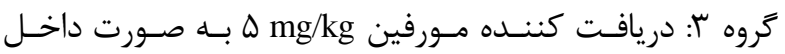
صفاقى گروه זٔ: دريافت كننده روغن با دوز mg/kg · به صورت داخـل صفاقى

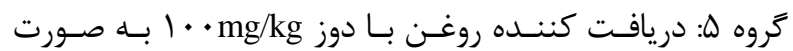
داخل صفاقى

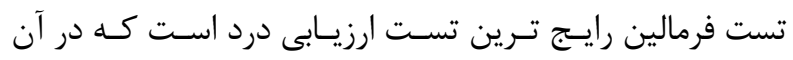

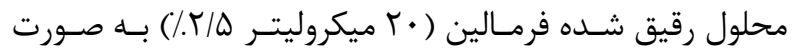
زيرجلدى به كف ياى حيـوان تزريـق مسىشـود و بــه دنبـال آن آن

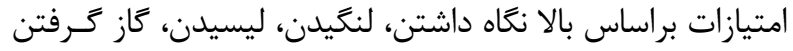

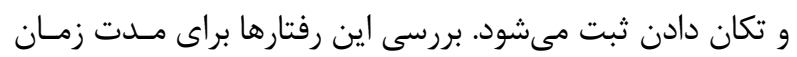

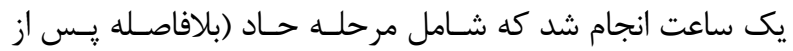
تزريق تا •ا دقيقه) است كه در اثر ورود سـوزن و تزريـق، فعـال

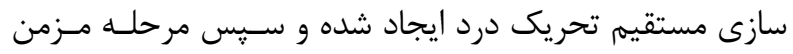

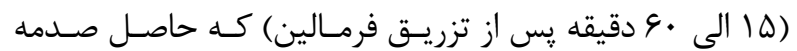

$$
\text { بافتى ناشى از عامل التهابزاى فرمالين است. }
$$

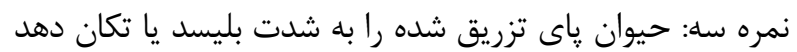

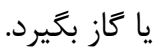

نمره دو: زمانى كه حيوان پاى تزيق شده را بدون تماس با سطح بالا نغاه دارد. نمره يك: حيوان پاى تزريق شده را بر سطح مى گذارد، ولى وزن

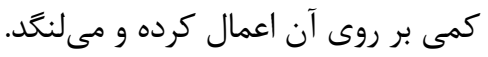

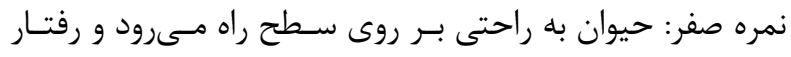
خاصى ناشى از درد نشان نمى دهدي.

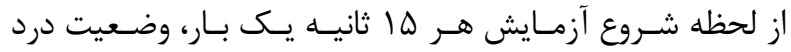

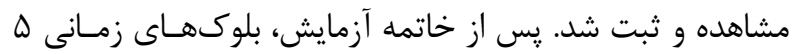

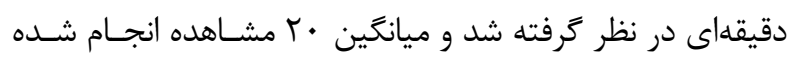
در ه دقيقه، بـه عنـوان شـدت درد يـاـ Pain Rating در بلـوكى مذكور يادداشت شد. به طور كلـى تزريـق زيـر جلـدى فرمـالين

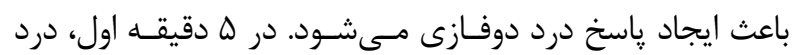

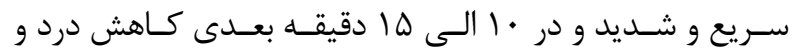

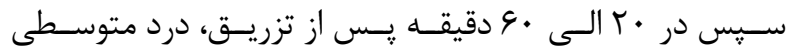
مشاهده مىشود. در اين بررسى براى مقايسه بهتـر، سـطح زيسـر

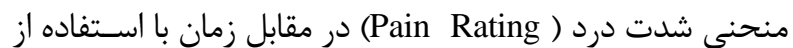
روش ذوزنقهاى، از زمان صفر يعنى تزريق فرمالين تا دقيقـه .

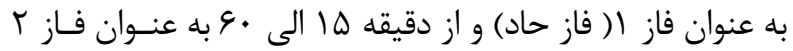

مىشود. در صورت عدم كنترل التهاب، مهـاجرت لوكوسـيتهـا، آنزيم هاى يروتئوليتيك (تجزيه كننده يروتئين) و متابوليتهاى

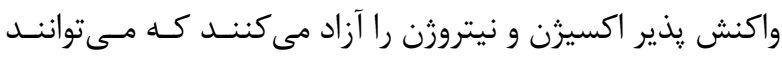
سمى باشند و باعث آسيب بافت شوند (TV).

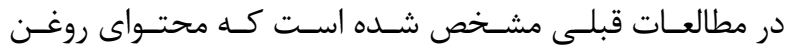

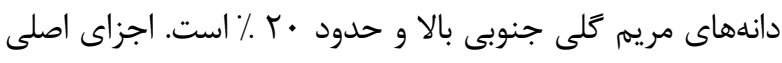

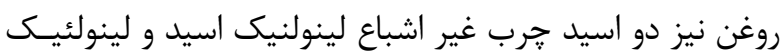

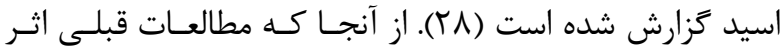
ضددرد و ضدالتهاب لينولئيك اسيد و لينولنيك اسـيد را نشـان

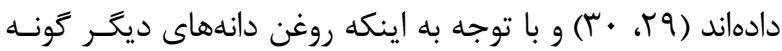
(S. hisponica ) Salvia نداشته است، در اين مطالعه براى اولين بـار اتـر ضـددرد روغـن حاصل از دانههاى كونه انحصارى S. sharifii با آزمون فرمـالين

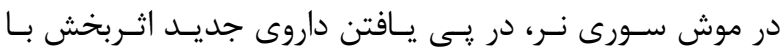
عوارض كمتر به عنوان ضددرد، بررسى شد.

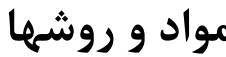

\section{جمع آورى گياه و تهيه روغن دانهها}

دانههاى كياه (Salvia sharifii Rech. F. \& Esfand) از اسـتان هرمزگان تهيه شد و بعـد از شناسـايى علمسى توسـط هربـاريوم

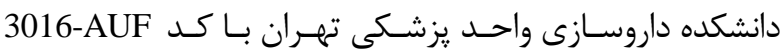
ذخيره شد. جهت تهيه روغن ثابت از حلال ان -هكَان و دستخاه

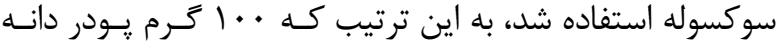
مريم كلى جنوبى براى مدت 9 ساعت عصاره گيرى شد و سيس

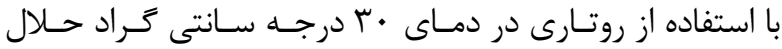
تبخير شد. روغن خالص حاصله به ويال مخصـوص منتقـل و در يخجال و دور از نور نغه دارى شد.

\section{آزمون فارماكولوزيك}

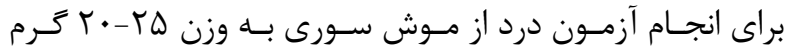
استفاده شد. اين حيوانات از دانشگاه علوم يزشكى شهيد بهشتى

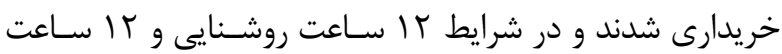

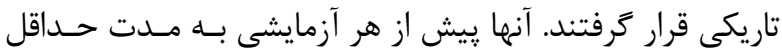

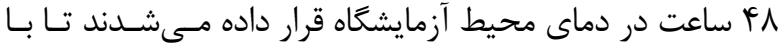
محيط ساز گار شوند. در طى اين مدت حيوانات به طور آزادانه به

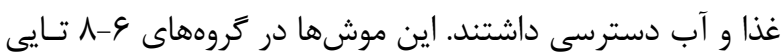
به ترتيب زير در نظر زرفته شدند: أروه ا: كنترل (روغن بادام شيرين به عنـوان حامـل به صورت داخل صفاقى) 
اصـلى روغـن دانـه هـاى ايـن خيـاه شـامل رالميتيـك اسـيد، لينولنيك اسيد، لينولئيك اسيد، آراشيديك اسيد و اسـتئاريك اهـ

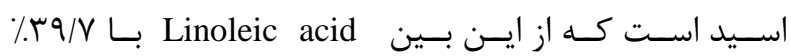

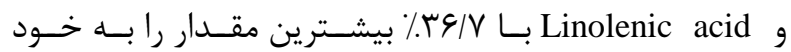

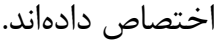

Salvia sharifii ) بررسى اثرات ضــددردى روغـن دانــه Rech. F. \& Esfand

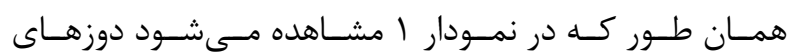

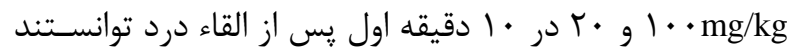
سبب كاهش سطح زير منحنى نمره درد در مقايسـه بـا تـروه

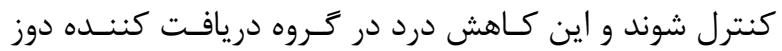

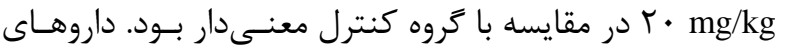
ضددرد استاندارد مورفين و مفناميك اسيد نيز بخوبى اثـرات و

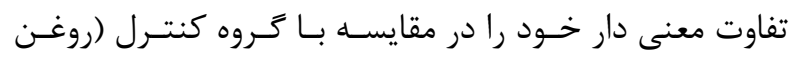

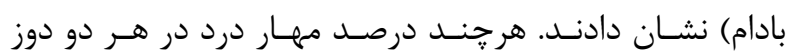
نسبت به گروهراى استاندارد كمتر بود (جدول ؟بر).

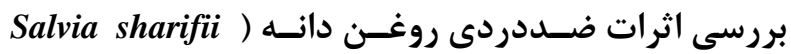
Rech. F. \& Esfand

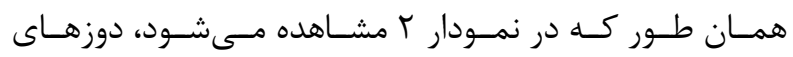

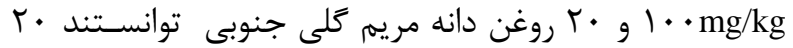
تا •و دقيقه يس از القاء درد سبب كاهش سطح زيـر منحنسى

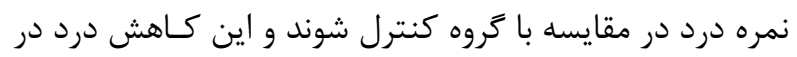

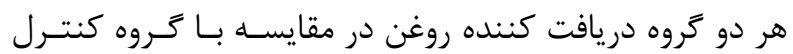

(فاز مزمن) محاسبه مىشود. داده هاى حاصل از مطالعه توسـط

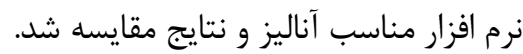

$$
\text { PAIN RATING }=\frac{1 T_{1}+2 T_{2}+3 T_{3}}{T I M E B L O C K(S E C)}
$$

$\%$ INHIBITION $=\frac{A U C_{\text {CONTROL }}-A U C_{T E S T}}{A U C_{\text {CONTROL }}} \times 100$

$$
\text { آناليز آمارى }
$$

داده هاى حاصل از هـر خـروه بـر حسب ميـانخين بــه اضـافه

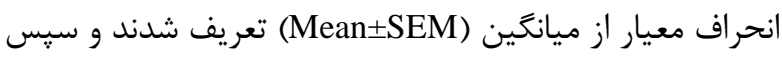

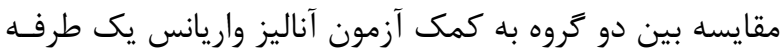
و مقايسه بين گروهها به وســيله آزمــون (one way ANOVA)

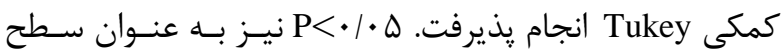
معنى دارى در نظر گرفته شد.

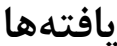

نتايج حاصل از آناليز روغن دانه كياه مريم كَلى جنـوبى

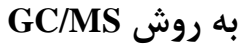

روغـن دانـهـــاى گيـاه Salvia sharifii داراى ظـاهرى نســبتا شفاف و زرد رنت است كه در مطالعات قبلى نيز توســ دكتـر عسكر رِناه و همكارانش تركيبـات تشـكيل دهنــده روغـن دانـهـ

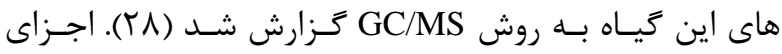

\begin{tabular}{|c|c|c|c|c|}
\hline ميزان (٪) & $\mathbf{K I}^{\ddagger}$ & $\mathbf{K I}^{\dagger}$ & نام تركيب " & رديف \\
\hline $9 / 4$ & 1941 & 1918 & پالميتيك اسيد & 1 \\
\hline rq/V & $r \cdot V \varphi$ & $r \cdot V I$ & لينولئيك اسيد & r \\
\hline re/V & $r l \cdot \Lambda$ & 5111 & لينولنيك اسيد & r \\
\hline$r / 1$ & TIYA & TITD & استئاريك اسيد & f \\
\hline .11 & grt & TrMt & آراشيديك اسيد & $\Delta$ \\
\hline$\Lambda \Lambda$ & & & جمع كل & \\
\hline
\end{tabular}

جدول ا. تركيبات شناسايى شده در روغن دانه هاى گياه مريم كلى جنوبى(Salvia sharifii Rech. F. \& Esfand)

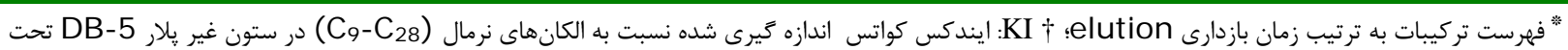

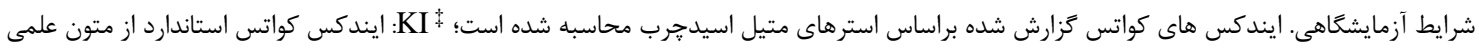

\begin{tabular}{|c|c|c|}
\hline درصد مهار درد در فاز مزمن & درصد مهار درد در فاز حاد & 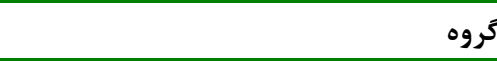 \\
\hline$r V / L F$ & $\Delta F / l$. & مفناميك اسيد \\
\hline$V \cdot / 1 Q$ & NN/TH & 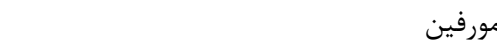 \\
\hline$r \cdot / \uparrow \wedge$ & rT/Vq & روغن دانه مريم كلى جنوبى ( r mg/kg) \\
\hline GY/VT & $r t / 4$ & روغن دانه مريم كلى جنوبى ( mg/kg " ( ) \\
\hline
\end{tabular}

جدول r. مقايسه درصد مهار درد در دو فاز حاد و مزمن آزمون فرمالين در گروههاى مورد مطالعه 
بحث

در اين مطالعه، براى اولين بار اثرات ضددردى روغــن دانـهـــاى

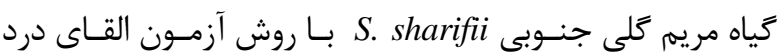
ناشى از تزريق كـف يـايى فرمـالين در مــوش سـورى نـر مــورد

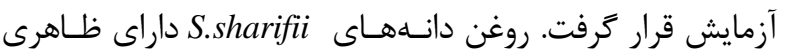
نسبتا شفاف و زرد رنت است كه در مطالعات قبلى توسط دكتر

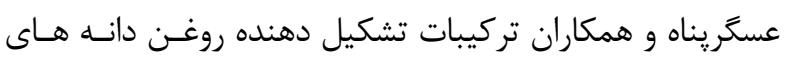

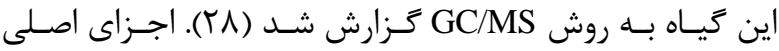

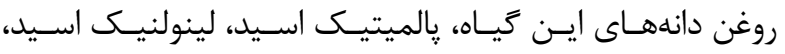

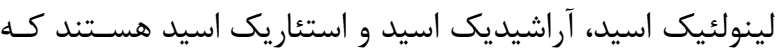

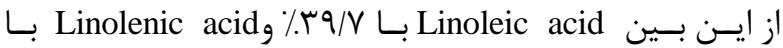

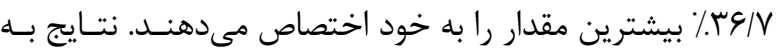

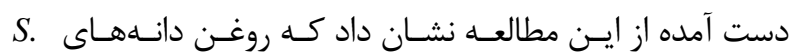
sharifii ضددردى معنى دار به ترتيب در فاز حـاد و مـزمن درد ناشسى از تزريق كف يايى فرمالين دارد. اين اثر ضددردى قابل مقايسـه بــا داروهاى ضددرد استاندارد مورفين و مفناميك اسيد بود. همانطور كه بيشتر اشاره شد از تركيباتى كه بيشـترين مقـدار را در روغن دانههاى مريم كلى جنوبى به خود اختصاص مسى دهـد،

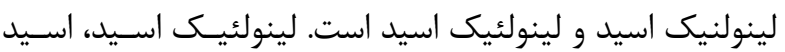

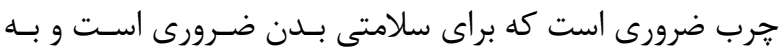

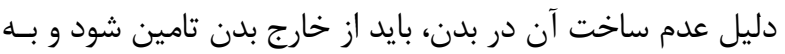

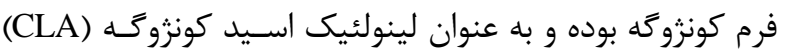
مطرح اسـت. از ديخـــ گياهـانى كـهـ روغـن آن سرشـار از اسـيد

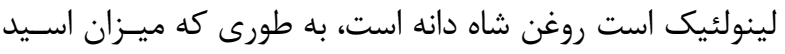

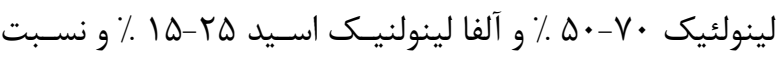

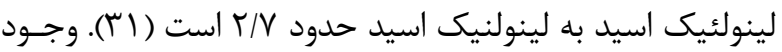

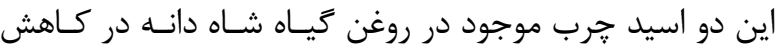

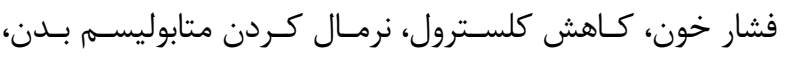

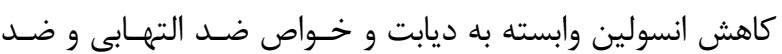
دردى و بهبودى بيمارى آرتريت موثر است (Tr).

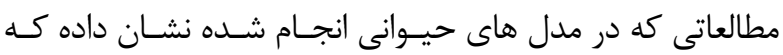

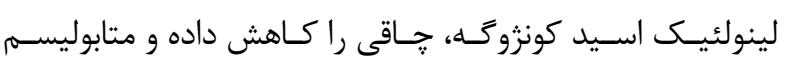

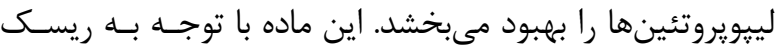

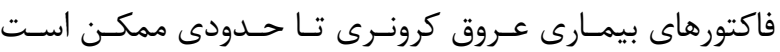

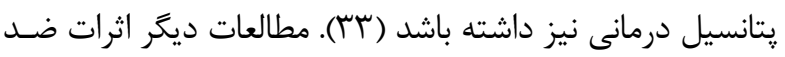

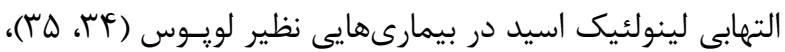

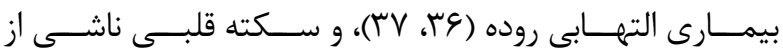

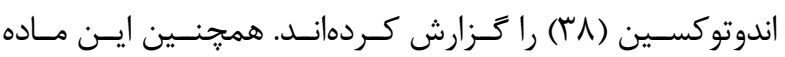

معنى دار بود. داروهاى ضددرد استاندارد مـورفين و مفناميـك اسيد نيز بخوبى اثرات و تفاوت معنى دار خود را در مقايسه بـا كروه كنترل (روغن بادام) نشـان دادنـد. درصـد مهــار درد فـاز مزمن در گروه دريافت كننده دوز mg/kg ق قابـل مقايسـه بـا گروه مفناميك و درصد مهار درد فاز مـزمن در حَروه دريافت كننده دوز mg/kg · • إبل مقايسه با مورفين بود (جدول r).

\section{Effect of Salvia sharifii seed's oil} on Acute phase of the formalin test

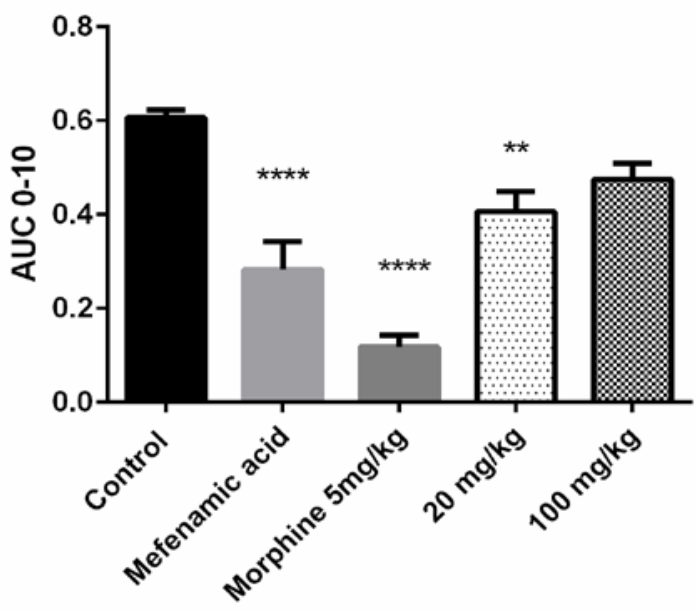

Groups

نمودار ا. اثرات ضد دردى S. sharifii در مقايسه با مفناميك اسيد و مورفين در فاز حاد تست فرمالين. دادهها بيانكر Mean_SEM است؛

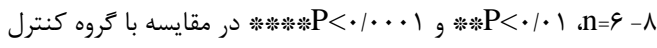

Effect of Salvia sharifii seed's oil on Chronic phase of the formalin test

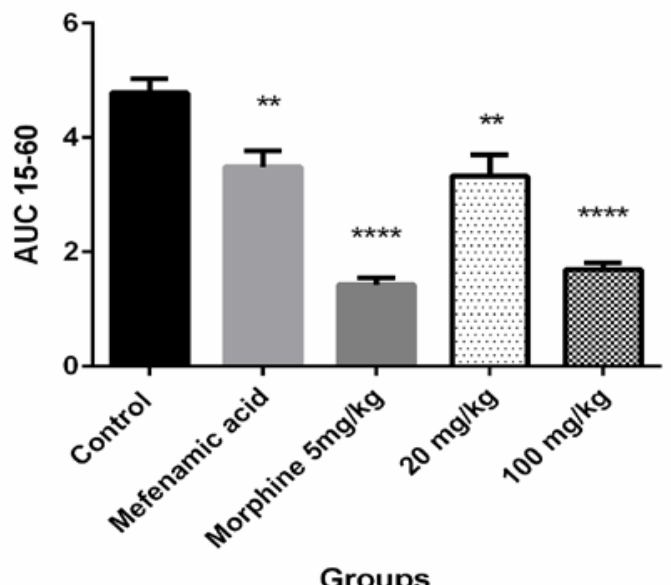

نمودار r. اثرات ضد دردى S. sharifii در مقايسه با مفناميك اسيد

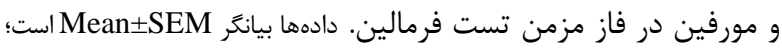

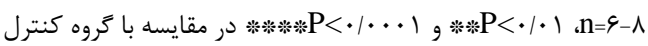


انتقال عصبى كلوتامات شد. همجٍنين لينولئيك اســيد بـهـ طـور

قابل توجهى باعث بهبودى رفتار افسردگى در موش شد (FT)

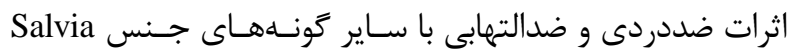
يیش از اين گزارش شده است. از جمله اثرات ضددردى در مدل

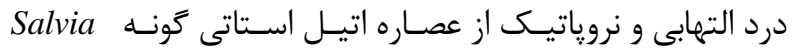
divinorum تركيبات فعال دى ترينـى مانــد Salvinorin A, Bـا اكونيست

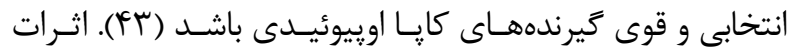
ضددردى و ضدالتهابى به ترتيب در مـدلهـاى درد hot plate و و

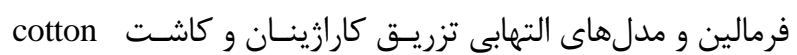

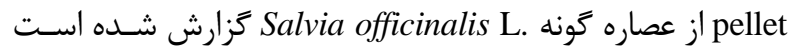
(FF) (FF). به علاوه اثرات ضددردى و ضـدالتهابى در مـدلهـاى درد tail flick و و مدلهاى التهابى تزريق اسيد استيك و نيز xylene-induced ear oedema از عصاره آبى دانههاى گونه Salvia leriifolia تركيبات موثر موجود در گونههاى مختلف Salvia اثرات زَارش

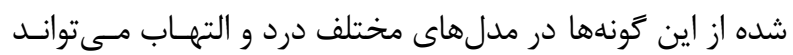
متفاوت باشد و قابل بحث و بررسى است.

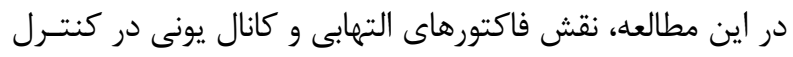

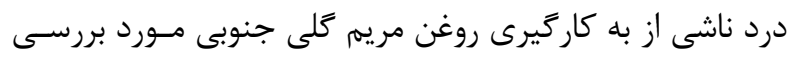

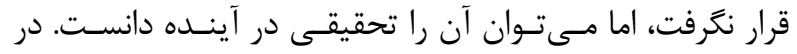
نتيجه، ممكن است بخشى از اثرات ضددردى اين كياه بـه دليـل

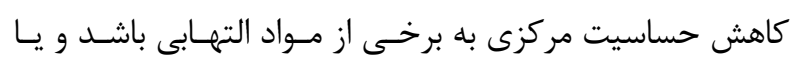

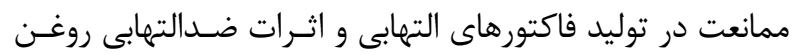
كه سبب كاهش ياسخ درد شده است. بنابراين ممكن اسـت كـهـ

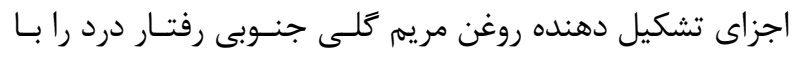

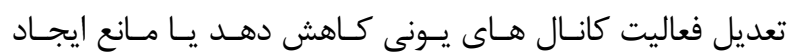
فاكتورهاى التهابى يا خنثى سـازى آنهـا شـود. همـان طـور كـهـ ززارشهاى متعدد در مورد فعاليت ضددرد آلفالينولنيك اسيد و

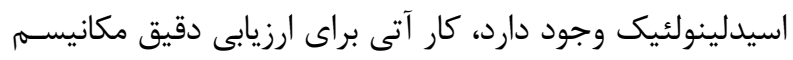
اثر ضددرد اين مواد خالص در آزمايشگاه يِيشنهاد مىشود. البته، مسموميت آلفالينولنيك اسيد نيز از مسائل مهمى است كه بايسد

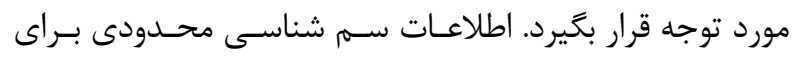

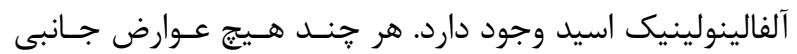
جدى اعلام نشده است، بـا ايـن حـال مطالعـهاى بــين سـرطان يروستات و رزيم غذايى در اروگوئه، شواهد ارتباط بين ايسن دو را

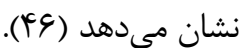
امروزه بيشتر مردم دنيا به جاى اسـتفاده از داروهــاى شـيميايى سعى مى كنند براى جلوگيرى از ابتلا به بيمـارى درد مفاصـل و و

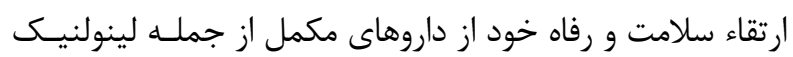

TNF و بيـان COX-2 را كــهـ جــزء فاكتورهــاى اصـلى التهــاب هستند را كاهش مى مهدد. مطالعه تاثير لينولئيك اسيد در مدل آرتريت ناشى از آنتى بادى كلازن نشان داده كه موشهايى كه از CLA تغذيه كردند امتيـاز

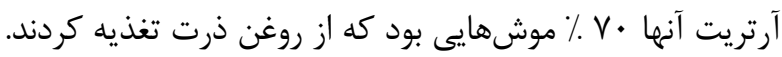

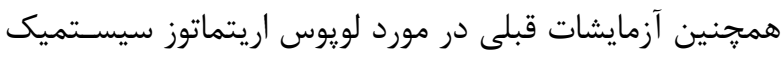

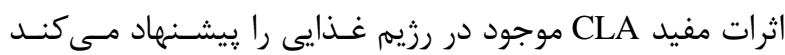

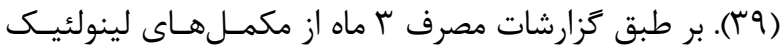

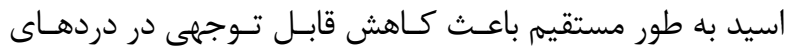
مفاصل و خشكى صبحكاهى و سطح ESR، RF ، RF مىشود. جزء اصلى ديخر تشكيل دهنده روغن اين گياه، لينولنيك اسـيد،

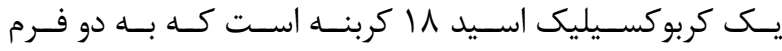
آلفالينولنيك اسيد (ALA) و كامالينولنيك اسيد (GLA) استـ نوعى از آن كه در اسيد جـــب ضـرورى كَياهـان موجـود اسـت،

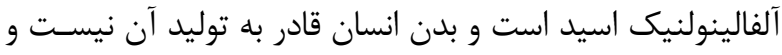

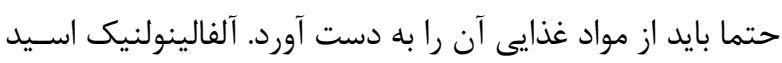
پيش ساز دو اسيد جرب ديخر تحت عنوان ايكوزاينتانوئيك اسيد

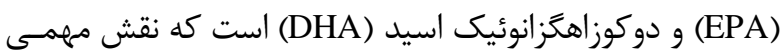

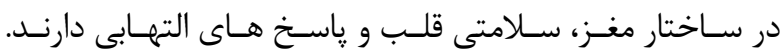
لينولنيك اسيد باعت حفظ ساختار و عملكـرد ميوكـارد شــده و

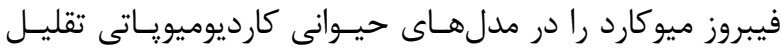

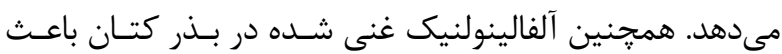

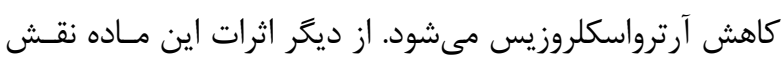

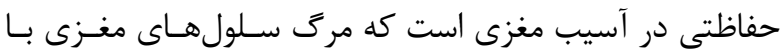

كمك لينولنيك اسيد جلوگيرى مىشود ( • (†). در بررسىهاى انجام شده در ارتباط با رزيم هاى غـذايى حـاوى آلفالينولنيـك اسـيد، كـاهش بيـان COX-2 و افـزايش آيويتــوز سلولهاى هياتوما است. ALA باعث محدود كردن سـايز تومـور شده و از تكثير سلولهاى سرطانى جلوگيرى مى كند. ايسن مـاده رشد سلولهاى سرطانى سينه و كردن رحمى را از طريـق كـاهش

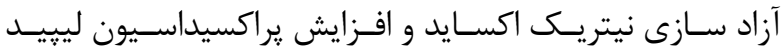

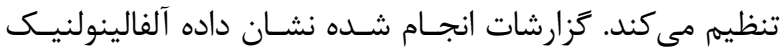
اسيد داراى اثر ضد التهاب در سطوح جشمى و سلولهـاى ايسى تليال قرنيه است (1) (1). (1).

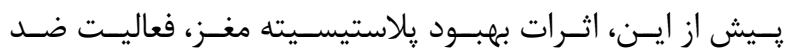

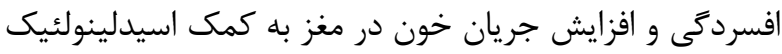

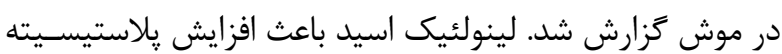
عصبى در سـطح مولكـولى و سـلولى گرديـد و منجــر بـهـ بيـان يروتئين هاى كليدى مرتبط با عملكرد سينايسى و بهبود مسـير 


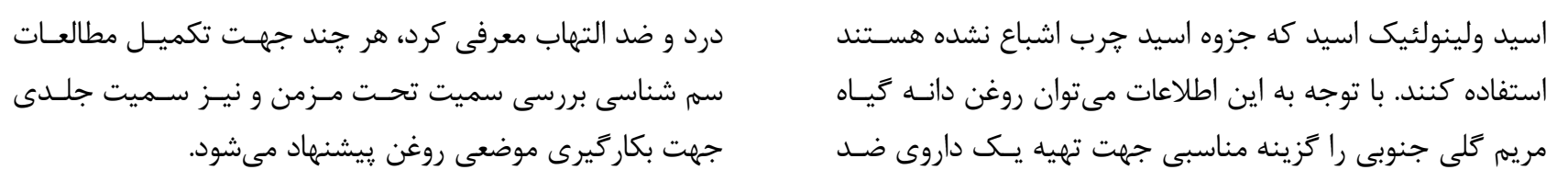

\section{REFERENCES}

1. Ghassemi Dehkordi N, Sajjadi SE, Ghanndadi A, Amanzadeh Y, Azadbakht M, Asghari GR, et al. Iranian herbal pharmavopoeia (IHP). Hakim Health Sys Res 2003;16:63-9.

2. Sharafzadeh S, Alizadeh O. Some medicinal plants cultivated in Iran. J Appl Pharm Sci 2012;2:134-7.

3. Imanshahidi M, Hosseinzade H. The pharmacological effect of Salvia species on the central nervous system. Phytother Res 2006;20:427-37.

4. Kuzma L, Skrzypek Z, Wysokinska H. Diterpenoids and triterpenoid in hairy roots of salvia sclarea. PCTOC 2006;4:171-9.

5. Lu Y, Foo LY. Polyphenolics of Salvia-a review. Phytochemistry 2002;59:117-40.

6. Thangaraju M, Rameshbabu J, Vasavi H, llanchezhian S, Vinitha R, Sachdandam. The salubrious effect of tamaxifen on serum marker enzymes, glycoproteins, and Lysosomal enzymes level in breast cancer women. Mol Cell Biochem 1998;185:85-94.

7. Mark C, Lesley B. Herbs and Natural Supplements: An evidence based guide. Churchill Livingstone Australia 2010;1013-8.

8. Caliskan O, Ayan AK, Cirak C. Seedling quality of common sage (Salvia officinalis L.) as affected by seedling production methods. Commun Biometry Crop Sci 2006;1:106-10.

9. Menq XC, Hou JC, Jiaq Y. Salvia miltiorrhizae in the treatment of the viral myocarditis. Zhonoqquo Zhonq Xi Yi Jie Za Zhi 1992;12:345-7, 324-5.

10. Takeo S, Tanonaka K, Hirai K, Kawaqachi K, Oqawa M, Yaq A, et al. Beneficial effect of tan-shen, an extract from the root of Salvia, on post-hypoxic recovery of cardiac contractile force. Biochem Pharmacol 1990;40:1137-43.

11. Baricevic D, Sosa S, Della Loggia R, Tubaro A, Simonovska B, Krasna A, et al. Topical anti-inflammatory activity of Salvia officinalis L. leaves; the relevance of ursolic acid. J Ethnopharmacol 2001;75:125-32.

12. Kianbakht S, Abasi B, Perham M, Hashem Dabaghian F. Antihyperlipidemic Effect of Salvia officinalis L. Leaf Extract in Patient with Hyperlipidemia: A Randomized Double-Blind Placebo-Controlled Clinical Trial. Phytother Res 2011;25:1849-53.

13. Sajjadi Se, Ghannadi A. Essential oil of the Persian sage, Salvia rhytidea Benth. Acta Pharm 2005;55:321-6.

14. Lu Y, Foo Y. Polyphenolics of Salvia--a review. Phytochemistry 2002;59:117-140.

15. Ahmadi Sh, Babakhanlu P, Karimifar Ma. Medicinal Plants of Lorestan. Yafte 2010,11:85-100.

16. Mozaffarian V. A Dictionary of Iranian Plant Names. Tehran: Farhang Moaser Pub, 1996. [In Persian]

17. Soltanipoor MA. Medicinal plants of the Geno protected area. Research Center Agricultural and Natural Resources of Hormozgan Province. Pajouhesh-VA-Sazandegi 2005;68:27-37. [In Persian]

18. Farjam Mh, Rustaiyan A, Ezzatzadeh E, Jassbi AR. Labdane-Type Diterpene and Two Flavones from Salvia Sharifii Rech. F and Esfan and their Biological Activities. Iran J Pharm Res 2013;12:395-400.

19. Najafi S, Mousavi M, Shafeghat M. Phytochemical composition, antioxidant and antimicrobial properties of Medical Plant Salvia sharifii Rech. F. \& Esfand. IJIDTM 2016;71:33-9. [ In Persian]

20. Jill MT, Navindra PS, Chengshui Z, Muraleedharan GN, Richard AM, Srinivas NR. Tart cherry anthocyanins suppress inflamemation-induced pain behavior in rat. Behav Brain Res 2004;153:181-8.

21. Tzulker R, Glazer I, Bar-IIan I, Holland D, Aviram M, Amir R. Antioxidant Activeity, polyphenol content and related compounds in different fruit juices and homogenates prepared from 29 different pomegranate accessions. $\mathrm{J}$ Agric Food Chem 2007;55:9559-67.

22. Ehrich EW, Dallob A, Delepeleire I, Riendeau D, Yuan W, Porras A, et al. Characterization of rofecoxib as a cyclooxygenase 2 isoform inhibitor and demonstration of analgesia in the dental pain model. Clin Pharmacol Ther 1992;65:336-47.

23. Lynch MA. Long-term potentiation and memory. Physiol Rev 2004;84:87-136. 
24. Kavvadias D, Sand P, Youdim KA, Qaiser MZ, Rice-Evans C, Baur R, et al. The flavones hispidulin, a benzodiazepine receptor ligand with positive allosteric properties, traverses the blood brain barrier and exhibits anticonvulsive effect. Br J Pharmacol 2004;142:811-20.

25. Pereira P, Tysca D, Oliveira P, da Silva Bruum LF, Picada JN, Ardenghi P. Neurobehavioral and genotoxic aspects of rosemarinic acid. Pharmacol Res 2005;52:199-203.

26. al-Sereiti MR, Abu-Amer KM, Sen P. Pharmacology of rosemary (Rosmarinus officinalis Linn.) and its therapeutic potential. Indian J Exp Biol 1992;37:124-30.

27. Melo GAN, Fonseca JP, Oliveira Farinha Th, Pinho RJ, Damião MJ, Grespan R, et al. Anti-inflammatory activity of Salvia officinalis L. J Med Plants Res 2010;6:4934-39.

28. Alipour-Gougeh S, Asgarpanah J. Essential and fixed oil chemical composition of the seeds from the endemic species Salvia sharifi Reach. f. \& Esfand. J Chil Chem Soc 2015;60:2695-7.

29. Johnson GH, Fritsche K. Effect of dietary linoleic acid on markers of inflammation in healthy persons. A systematic review of randomized controlled trials. J Acad Nutr Diet 2012;112:1029-41.

30. Kapoor R, Huang YS. Gamma linolenic acid: an antiinflammatory omega-6 fatty acid. Curr Pharm Biotechnol 2006;7:531-4.

31. Koga T, Nonaka M, Gu JY, Sugano M. Linoleic and alpha Linolenic acids differently modify the effects of elaidic acid on polyunsaturated fatty acid metabolism and some immune indices in rats. Br J Nutr 1997;77:645-56.

32. Hansen HS. New biological and clinical roles for n-3 fatty acids. Nutr Rev 1994;52:162-7.

33. Noone EJ, Roche HM, Nugent AP, Gibney MJ. The effect of dietary supplementation using isomeric blends of conjugated linoleic acid on lipid metabolism in healthy human subjects. Br J Nutr 2007;88:243-51.

34. Yang M, Pariza MW, Cook ME. Dietary conjugated linoleic acid protects against end stage disease of systemic lupus Erythematosus in the NZB/W F mouse. Immunopharmacol Immunotoxicol 2000;16:433-49.

35. Bergamo P, Maurano F, Rossi M. Phase 2 enzyme induction by conjugated linoleic acid improves lupus-associated oxidative stress. Free Radic Biol Med 2007;43:71-9.

36. Bassaganya-Riera J, Hontecillas R, Beitz Dc. Colonic anti-inflammatory mechanisms of conjugated linoleic acid. Clin Nutr 2002;21:451-59.

37. Bassaganya-Riera J, Reynolds K, Martino-Catt S, Cui Y, Hennighausen L, Gonzalez F, et al. Activation of PPAR gamma and delta by conjugated linoleic acid mediates protection from experimental inflammatory bowel disease. Gastroenterology 2004;127:777-91.

38. Miller CC, Park Y, Pariza MW, Cook ME. Feeding conjugated linoleic acid to animals partially overcomes catabolic responses due to endotoxin injection. Biochem Biophys Res Commun 1994;198:1107-12.

39. Nicolosi RJ, Rogers EJ, Kritchevsky D, Scimeca JA, Huth PJ. Dietary conjugated linoleic acid reduces plasma lipoproteins and early aortic atherosclerosis in hypercholesterolemic hamsters. Artery 1997;22:266-77.

40. Xiao YF, Kang JX, Morgan JP, Leaf A. Blocking effects of polyunsaturated fatty acids on Na + channels of neonatal rat ventricular myocytes. Proc Natl Acad Sci U S A 1995;92:11000-4.

41. Kim KB, Nam YA, Kim HS, Hayes AW, Lee BM. $\alpha$-Linolenic acid Nutraceutical, pharmacological and toxicological evaluation. Food Chem Toxicol 2014;70:163-78.

42. Lauritzen I, Blondeau N, Heurteaux C, Widmann C, Romey G, Lazdunski M. Polyunsaturated fatty acids are potent neuroprotectors. EMBO J 2000;19:1784-93.

43. Hosseinzadeh H, Haddadkhodaparast MH, Arash AR. Antinociceptive, antiinflammatory and acute toxicity effects of Salvia leriifolia Benth seed extract in mice and rats. Phytother Res 2003;17:422-5.

44. Qnais EY, Abu-Dieyeh M, Abdulla FA, Abdalla SS. The antinociceptive and anti-inflammatory effects of Salvia officinalis leaf aqueous and butanol extracts. Pharm Biol 2010;48:1149-56.

45. Simón-Arceo K, González-Trujano ME, Coffeen U, Fernández-Mas R, Mercado F, Almanza A, et al. Neuropathic and inflammatory antinociceptive effects and electrocortical changes produced by Salvia divinorum in rats. J Ethnopharmacol 2017;206:115-24.

46. Carayol M, Grosclaude P, Delpierre C. Prospective studies of dietary alpha-linolenic acid intake and prostate cancer risk: a meta-analysis. Cancer Causes Control 2010;21:347-55. 